\title{
Long-Term Survival in Triple-Vessel Disease: Hybrid Coronary Revascularization Compared to Contemporary Revascularization Methods
}

\author{
Craig Basman ${ }^{1}$, Jonathan Hemli ${ }^{2}$, Michael Kim ${ }^{1}$, Karthik Seetharam ${ }^{1}$, Derek Brinster ${ }^{1}$, \\ Luigi Pirelli ${ }^{1}$, Chad Kliger ${ }^{1}$, S Scheinerman ${ }^{1}$, Varinder Singh ${ }^{1}$, and Nirav Patel ${ }^{1}$ \\ ${ }^{1}$ Lenox Hill Hospital \\ ${ }^{2}$ Affiliation not available
}

June 8, 2020

\begin{abstract}
Background: Hybrid coronary revascularization (HCR) constitutes a left internal mammary artery (LIMA) graft to the left anterior descending (LAD) coronary artery, coupled with percutaneous coronary intervention (PCI) for non-LAD lesions. This management strategy is not commonly offered to patients with complex multi-vessel disease. Our objective was to evaluate 8-year survival in patients with triple-vessel disease (TVD) treated by HCR, compared with that of concurrent matched patients managed by traditional coronary artery bypass grafting (CABG) or multi-vessel PCI. Methods: A retrospective review was undertaken of 4805 patients with TVD who presented between January 2009 and December 2016. A cohort of 100 patients who underwent HCR were propensity-matched with patients treated by CABG or multi-vessel PCI. The primary end-point was all-cause mortality at 8 years. Results: Patients with TVD who underwent HCR had similar 8-year mortality (5.0\%) as did those with CABG (4.0\%) or multi-vessel PCI (9.0\%). A composite end-point of death, repeat revascularization, and new myocardial infarction, was not significantly different between patient groups (HCR 21.0\% vs. CABG 15.0\%, p = 0.36; HCR $21.0 \%$ vs. PCI $25.0 \%, \mathrm{p}=0.60$ ). Despite a higher baseline SYNTAX score, HCR was able to achieve a lower residual SYNTAX score than multi-vessel PCI $(\mathrm{p}=0.001)$. Conclusions: In select patients with TVD, long-term survival and freedom from major adverse cardiovascular events (MACE) after HCR are similar to that seen after traditional CABG or multi-vessel PCI. HCR should be considered for patients with multi-vessel disease, presuming a low residual SYNTAX score can be achieved.
\end{abstract}

\section{ABBREVIATIONS}

$\mathrm{ACCF}=$ American College of Cardiology Foundation

$\mathrm{AHA}=$ American Heart Association

$\mathrm{BMI}=$ body mass index

$\mathrm{CABG}=$ coronary artery bypass grafting

$\mathrm{CHF}=$ congestive heart failure

$\mathrm{COPD}=$ chronic obstructive pulmonary disease

DES $=$ drug-eluting stent

$\mathrm{ESRD}=$ end-stage (dialysis-dependent) renal disease

FREEDOM $=$ Future Revascularization Evaluation in Patients with Diabetes

Mellitus: Optimal Management of Multivessel Disease 
$\mathrm{HCR}=$ hybrid coronary revascularization

$\mathrm{IQR}=$ interquartile range

ISR $=$ in-stent restenosis

$\mathrm{LAD}=$ left anterior descending coronary artery

LIMA $=$ left internal mammary artery

$\mathrm{LVEF}=$ left ventricular ejection fraction

$\mathrm{MACE}=$ major adverse cardiovascular events

$\mathrm{MI}=$ myocardial infarction

MIDCAB = minimally-invasive direct coronary artery bypass

$\mathrm{n} / \mathrm{a}=$ not applicable

NYHA $=$ New York Heart Association

$\mathrm{PCI}=$ percutaneous coronary intervention

$\mathrm{RCA}=$ right coronary artery

SYNTAX = SYNergy between percutaneous coronary intervention with TAXus

and cardiac surgery

$\mathrm{SD}=$ standard deviation

$\mathrm{SEM}=$ standard error of the mean

TVD $=$ triple-vessel (coronary artery) disease

INTRODUCTION:

Landmark trials have suggested that coronary artery bypass grafting (CABG) should be considered the revascularization method of choice in patients with multi-vessel disease $(1,2)$. The benefits of CABG in these patients are largely accrued by the unique advantages of the left internal mammary artery (LIMA) to left anterior descending (LAD) bypass graft, which, in itself, affords a significant long-term survival advantage, and which has consistently demonstrated 10-year patency rates well above $90 \%$ (3). On the other hand, saphenous venous grafts to non-LAD targets are more prone to atherosclerotic degeneration and failure, and have been observed to occlude as early as 1 year postoperatively in $6-32 \%$ of cases $(4,5)$. By contrast, angiographic surveillance has demonstrated that rates of clinically relevant in-stent restenosis (ISR) after percutaneous coronary intervention (PCI) are less than $5 \%$ at 1 year follow-up, especially with the increasing utilization of newer generation drug-eluting stents (DES) (6). One further potential pitfall of traditional CABG is an increased incidence of stroke, as compared to PCI $(1,2)$.

Hybrid coronary revascularization (HCR) affords the patient the advantages of the LIMA to LAD graft, usually completed via a minimally-invasive approach, coupled with PCI for all non-LAD lesions. Utilizing a minimal access, 'off-pump' technique to complete the LIMA to LAD bypass virtually negates the risk of stroke that is associated with traditional CABG, whilst also reducing the infection rate and the perioperative transfusion rate, and hastening recovery time by avoiding a median sternotomy $(7,8)$.

In the American College of Cardiology Foundation/American Heart Association (ACCF/AHA) Guidelines for Coronary Artery Bypass Graft Surgery, HCR, for the treatment of triple vessel disease (TVD), was denoted a Class IIb recommendation as an alternative method of revascularization to PCI or CABG, in an attempt to improve the overall risk-benefit ratio of the procedures (9). Despite the fact that the first HCR was performed more than two decades ago, this treatment option has constituted less than $0.5 \%$ of all CABG volume in the United States (10). A paucity of long-term data has undoubtedly contributed, at least in part, 
to the relative under-utilization of HCR. Consequently, we sought to evaluate the 8-year survival data after HCR for TVD, and we compared it with that of concurrent matched patients who had either traditional CABG via sternotomy or multi-vessel PCI.

\section{METHODS}

\section{Patients and Definitions}

A review was undertaken of all patients who underwent myocardial revascularization at our institution between January 2009 and December 2016. Of these patients, those who had intervention for TVD were selected for analysis.

We used the same definitions for stroke and myocardial infarction (long-term) as the SYNTAX trial (1). However, for periprocedural myocardial infarction (short-term outcome) we only included Type 1 MI (using the Third Universal Definition of Myocardial Infarction) that occurred on index hospital admission, which explains our low event rate (11). New-onset renal failure was defined as a non-dialysis dependent patient requiring one or more hemodialysis sessions post-procedure. Target vessel revascularization was defined as a repeat intervention for a prior stented lesion, either within the stent itself or within $5 \mathrm{~mm}$ of the stent, and/or a repeat procedure for a lesion that was previously surgically bypassed. We also included major adverse cardiovascular events (MACE) as a long-term clinical endpoint. Our definition of MACE denotes a composite end-point encompassing death, repeat revascularization and/or myocardial infarction. We did not include major adverse cardiovascular and cerebrovascular evens (MACCE) as a long-term clinical outcome. Instead we included stroke as a short-term clinical endpoint, as we felt that stroke 30 days post-revascularization is unlikely related to the revascularization method. For patients that underwent HCR, length of stay included the total hospital stay for both the MIDCAB and PCI. Our preferred method is to perform a MIDCAB-first approach, followed by interval PCI, typically within 4 to 6 weeks of surgery. However, select situations require a PCI-first approach. Among the PCI cohort in which revascularization was often performed on separate admissions, we defined length of stay as the days admitted for all hospitalizations combined. All clinical events were adjudicated by an independent clinical event committee (involving a cardiothoracic surgeon and interventional cardiologist).

The relative contraindications to HCR were the need for emergency revascularization, and/or severe pulmonary disease rendering the patient unable to tolerate single-lung ventilation. Patients with high BMI have been regarded by some investigators as being unsuitable for HCR; we did not withhold HCR from these patients, and, indeed, our experience with minimally-invasive direct coronary artery bypass (MIDCAB) in this patient population has been reported previously (12).

We analyzed propensity-matched patients who underwent HCR, CABG, or multi-vessel PCI for triple-vessel disease. Any patients who required concomitant non-coronary surgery, in addition to their revascularization procedure, were also excluded, as were patients who required emergency or salvage intervention, as well as patients who had prior cardiac and/or thoracic surgery.

\section{Surgical and Interventional Details}

Our technique for robotic-assisted LIMA to LAD bypass, constituting the MIDCAB component of HCR, has been described previously $(13,14)$. Briefly, the da Vinci Intuitive robot system (Intuitive Surgical Inc, Sunnyvale, CA, USA) was utilized for LIMA harvest. The LIMA to LAD anastomosis was completed 'off-pump', through an anterior, muscle-sparing, non-rib spreading, mini-thoracotomy, facilitated by a low-profile compression myocardial stabilizer. An intra-coronary shunt was used in all cases. Graft flow characteristics were assessed in the operating room using the Medistim VeriQ transit-time flow measurement system (Medistim USA Inc, Plymouth, MN, USA).

The PCI components of the HCR cases, as well as the interventions in those patients treated by PCI alone, were performed using standard techniques ( $~ 50 \%$ radial approach). All patients received either second or third generation drug-eluting stents (DES). We did not deny HCR to those patients that required 'complex PCI' (as defined by the NCDR (National Cardiovascular Data Registry) CathPCI Reg- 
istry: https://www.ncdr.com/WebNCDR/docs/default-source/public-data-collection-documents/cathpci_v4_codersdictionary_4-4.pdf?sfvrsn=2). All patients were maintained on dual antiplatelet therapy for at least one year after stent placement. The majority of our sternotomy CABG cases were completed 'offpump', our technique for which has been previously reported (15). All patients received a LIMA graft to the LAD.

\section{Calculation of SYNTAX Scores}

All baseline SYNTAX scores were calculated by an experienced interventional cardiologist who was blinded as to the treatment modality that was to be assigned to any particular patient. Baseline SYNTAX scores were derived from the initial coronary angiogram, prior to any intervention.

For those patients who underwent coronary artery bypass grafting (standard or hybrid coronary revascularization) the SYNTAX scores were calculated based on Farooq V et al's methodology for the calculation of residual SYNTAX score (16). In those patients that underwent MIDCAB-first HCR or multi-vessel PCI, the residual SYNTAX score was based on the final angiogram, obtained after the last stents were placed. In those patients who had PCI-first HCR, the residual SYNTAX score was calculated assuming patency of the LIMA to LAD graft. For the CABG cohort, residual SYNTAX score was calculated based on the combination of the initial angiogram together with the operation report, assuming patency of the bypass grafts to the target vessels.

\section{Data Analysis}

Study data were collected and managed using REDCap electronic data capture tools hosted at Lenox Hill Hospital (17). REDCap (Research Electronic Data Capture) is a secure, web-based application designed to support data capture for research studies.

Observed covariates at baseline included age, gender, body mass index, diabetes mellitus, cerebrovascular disease, chronic lung disease, peripheral vascular disease, dialysis-dependent renal failure, history of prior myocardial infarction, congestive heart failure, and left ventricular ejection fraction. To control for these confounding influences, we calculated propensity scores (or the probability of assignment to HCR, CABG, or multi-vessel PCI) using multivariable logistic regression for each patient. Patients who underwent HCR were matched with patients who underwent conventional CABG and with those who had multi-vessel PCI in a 1:1 ratio through a nearest neighbor-matching algorithm. In order to exclude bad matches, we instituted a caliper of 0.2 of the standard deviation of the logit of the propensity score. The Area Under the Curve for the ROC of the propensity model 0.74. The matched sample included a total of 300 patients, evenly distributed in each group

Longitudinal outcomes and survival to 8 years was estimated using Kaplan-Meier analysis and Cox proportional hazard regression. Patient characteristics and outcomes were compared using chi-square, Fisher's exact test, Student's t-test, or Wilcoxon-Mann-Whitney test, as appropriate. A chi-square test was used for categorical variables where the expected value for each cell was 5 or higher; if this assumption was not met, then Fisher's exact test was used. A $p$ value of less than 0.05 was considered to be statistically significant. Statistical analyses were performed with the IBM Statistical Package for the Social Sciences (SPSS) for Windows, version 22.0 (IBM Corporation, Armonk, NY, USA).

Mean ( \pm SEM) follow-up was $7.14 \pm 0.12$ years for all patients. All-cause mortality up to a maximum of 8 years was obtained by querying the National Death Index (NDI) to determine dates of death up to December 31,2016 . Short-term outcomes, such as length of hospital stay, peri-procedural stroke, myocardial infarction (MI) or new-onset renal failure was evaluated via a retrospective chart review on our hospital systems electronic medical records. The long-term follow up for repeat revascularization, myocardial infarction and target vessel revascularization was achieved through a chart review of our hospital system and our referring hospital systems electronic medical records. The majority of patients had follow up greater than 1 year, however there were patients (18 total) that we were unable to find proper follow-up after hospital discharge.

\section{RESULTS}




\section{Patient Characteristics}

Over the study period, a total of 4805 patients had treatment for triple-vessel coronary artery disease at our institution. Of these, 826 patients $(17.2 \%)$ were excluded from analysis, for reasons as previously stated. Of the remaining 3979 patients with 'stable' TVD, 100 individuals (2.5\%) underwent HCR, 1258 (31.6\%) had classic CABG via sternotomy, whereas the remaining 2621 patients $(65.9 \%)$ had multi-vessel PCI. Our final study population comprised the 100 patients who underwent HCR, propensity-matched with 100 patients each who underwent CABG or multi-vessel PCI for triple-vessel disease (Figure 1). Patient demographics are summarized in Tables 1 and 2.

The baseline SYNTAX score was significantly higher in the CABG cohort than in the HCR group (32.2 \pm 7.9 vs. $28.9 \pm 10.6$, respectively, $p=0.018)$, and, similarly, it was higher in the HCR patients than in those who underwent PCI only $(28.9 \pm 10.6$ vs. $22.1 \pm 7.6, p<0.01)$.

\section{Short-Term Outcomes}

Thirty-day mortality was $0 \%$ in all patient groups. There was no peri-procedural stroke, myocardial infarction (MI) or new-onset renal failure, regardless of the technique of myocardial revascularization employed (Table $3)$. Hospital length of stay was shorter for those patients that underwent HCR ( $5.7 \pm 7.5$ days) than for those who had CABG $(7.5 \pm 3.4$ days) $(p=0.01)$, but was still longer than it was for the PCI group $(2.0$ \pm 2.2 days $)(p<0.0001)$.

There was no significant difference in residual SYNTAX score between those patients who had HCR $(4.5 \pm$ $4.4)$ and those who underwent CABG $(5.2 \pm 4.7)(p=0.31)$. However, despite the HCR cohort having a higher SYNTAX score at baseline than those patients who underwent multi-vessel PCI, the residual SYNTAX score was significantly lower after HCR than it was after PCI $(4.5 \pm 4.4$ vs. $7.1 \pm 6.5$, respectively, $p=$ 0.001) (Table 3).

\section{Long-Term Outcomes}

The primary end-point of all-cause mortality at 8 years was not significantly across any of the three treatment groups (HCR 5.0\%vs. CABG 4.0\% vs. PCI 9.0\%) (Figure 2). There was also no significant difference in the incidence of repeat revascularization between the three patient groups (HCR $16.0 \%$ vs. CABG $11.0 \%$ vs. PCI 18.0\%) (Figure 3). Repeat revascularization rates on a previously treated coronary artery ('target vessel revascularization') were similarly comparable between patient cohorts (HCR 6.0\% vs.CABG 5.0\% vs. PCI $10.0 \%$ ) (Table 4). A composite MACE end-point encompassing death, repeat revascularization and new myocardial infarction did not demonstrate significant difference at 8 years, regardless of the technique of revascularization (Figure 4).

\section{DISCUSSION}

HCR has not, as yet, become widely employed as a mainstream option for treating coronary artery disease, particularly for those patients who have more than just an isolated LAD lesion. Published data on HCR is relatively limited, with the majority of studies thus far being primarily single-center, non-randomized reports, incorporating only small to moderate patient numbers, with few exceptions $(18,19)$. At present, no randomized trials specifically compare HCR with CABG. To the best of our knowledge, there is only one other study to analyze propensity-matched data, comparing HCR to both CABG and multi-vessel PCI in patients with TVD (20). However, our study is thus far the only propensity-matched study comparing long-term clinical endpoints for all three revascularization methods.

For patients undergoing HCR, we prefer a MIDCAB-first approach, followed by interval PCI, typically within 4 to 6 weeks of surgery. This allows the surgical revascularization to be performed without concern for potential bleeding that may be associated with the dual antiplatelet therapy that is mandatory after PCI with DES. We have, nevertheless, previously described our satisfactory experience with MIDCAB in patients taking dual antiplatelet agents (21), results that have not necessarily been consistent amongst all surgical 
groups (22). More importantly, however, the MIDCAB-first approach allows the patency of the LIMA to LAD bypass graft to be interrogated during the subsequent PCI procedure.

A PCI-first HCR strategy was pursued in those patients who presented with a coronary syndrome in which the culprit lesion was deemed to be within one of the non-LAD vessels, or in those individuals in whom the angiographic severity and clinical import of at least one of the non-LAD stenoses was thought to be greater than that of the disease within the LAD itself. For these patients, subsequent LIMA to LAD grafting was undertaken on uninterrupted dual antiplatelet therapy.

Of the 100 patients in our final study population who underwent HCR, 72 had MIDCAB followed by PCI, whereas the remaining 28 had PCI prior to MIDCAB. We did not perform any cases of simultaneous MIDCAB and PCI, although this approach has been adopted by other investigators $(23,24)$. None of our MIDCAB patients required intraoperative conversion to sternotomy.

The primary end-point of our study, all-cause mortality at 8 years, was not significantly different across the three revascularization cohorts. Freedom from MACE at 8 years was also comparable between patient groups. However, despite having a higher SYNTAX score at baseline, those patients that underwent HCR ended up with a lower residual SYNTAX score did those who had multi-vessel PCI, reflective of a significant difference in the completeness of revascularization achieved. By contrast, HCR patients had similar residual SYNTAX scores to those patients managed by traditional CABG. Our data also shows that early complications from HCR were infrequent. The HCR cohort did benefit from a shorter length of hospital stay than did the CABG group.

The mean baseline SYNTAX score in our HCR cohort was $28.9 \pm 10.6$. In the SYNTAX trial, patients with TVD with similar, intermediate, SYNTAX scores demonstrated no significant difference in the incidence of MACE at 12 months, when the PCI group was compared to CABG (1). When this group was of patients was followed for 5 years, MACE rates were indeed found to be higher in the PCI cohort, but there was no significant mortality difference between treatment groups (25). Similarly, in diabetic patients with intermediate SYNTAX scores, the FREEDOM trial found that the composite end-point of death, MI and stroke at 5 years favored CABG over PCI, again with no significant mortality difference identified (2). These results suggest that, in the TVD patient population with intermediate SYNTAX scores, although mid-term survival is comparable across treatment arms, morbidity may be higher after PCI, particularly with respect to the increased incidence of repeat revascularization and new myocardial infarction. We suggest that it may be this group of patients that may be ideally suited to benefit from HCR.

The longer-term overall mortality rates in our patient groups were slightly lower than that observed in comparable individuals in some of the larger trials. It is our hypothesis that these low mortality rates are attributable, at least in part, to the low residual SYNTAX scores that were able to be achieved in each patient group, regardless of the technique of revascularization. There is good data to support the assertion that the completeness of revascularization (as quantified by the residual SYNTAX score) is a predictor of short-tomedium term MACE in patients with multi-vessel coronary artery disease undergoing PCI or CABG (2628). Our group has previously reported that a low residual SYNTAX score after HCR was associated with 8-year survival that was not significantly different than that seen after traditional CABG in patients with double-vessel coronary disease (29). Our current results suggest that HCR is also associated with favorable long-term results in patients with TVD, provided that the operators can achieve a low residual SYTNAX score.

This study is also one of the first thus far to demonstrate that HCR may be considered a reasonable method of revascularization in TVD patients with left main-stem involvement. Of the 24 patients with left main coronary disease who underwent HCR, there was only 1 death (4.2\%) at long-term follow up.

Sixteen patients who underwent HCR required repeat revascularization by 8 -year follow-up. Of these, only 6 $(37.5 \%)$ actually required a 'target vessel revascularization'. The remaining 10 patients $(62.5 \%)$ all required intervention for de-novo lesions. In those $6 \mathrm{HCR}$ individuals that required target vessel revascularization, 3 procedures were performed due to problems with the LIMA to LAD graft, whereas 3 interventions were 
undertaken in non-LAD vessels. The incidence of target vessel revascularization was not significantly different between the HCR, CABG and multi-vessel PCI groups; in the CABG population, 2 patients required a reintervention for the LIMA to LAD graft.

\section{STUDY LIMITATIONS}

Our study has several limitations to be acknowledged. Our data was derived from a retrospective review in a single institution. A multi-center approach, incorporating a larger sample size, would be more adequately powered to analyze more subtle differences between outcomes. Our patients were not randomized to a given revascularization strategy. Although the impact of this may be somewhat mitigated by the fact that the treatment for each patient was not selected by a single practitioner, but rather by a multidisciplinary heart team, the fact that the overwhelming majority of patients with TVD in our institution were treated by either CABG or multi-vessel PCI reflects an intrinsic selection bias for those individuals offered HCR.

Due to the differences in SYNTAX scores between patient groups, our data cannot be used to comment on the superiority of one revascularization strategy over another. The data does, however, afford us the opportunity to evaluate the effectiveness of a 'real-world' heart team approach to the management of patients with TVD. Residual SYNTAX score calculations in our CABG and PCI-first HCR patients assumed patency of all surgical bypass grafts; although suboptimal, it was not deemed appropriate to undertake formal angiography in asymptomatic patients for the sole purpose of calculating a residual SYNTAX score.

We were able to achieve $100 \%$ follow up for our primary end-point, namely, all-cause death at 8 years. We utilized the National Death Index as our primary source for 8-year survival data; though this methodology may somewhat underestimate true mortality (30). Patients that underwent multi-vessel PCI had a numerically higher amount of death than CABG or HCR, however this did not meet significance. We cannot exclude the possibility of a type II error, as our study size was limited. With respect to the other long-term outcomes that were reported, it is important to note that there were 15 patients in the CABG arm, 5 in the PCI group, and 3 in the HCR cohort, that were all lost to follow-up. Furthermore, we are unable to correct for the use of DAPT which may confound the long-term results of MACE.

Our institution has extensive experience with minimal-access, robotic-assisted LIMA to LAD grafting, as well as with complex PCI. Our results may, therefore, not be directly generalizable to other institutions who have less experience with either revascularization strategy. Similarly, the low perioperative stroke rate observed in our sternotomy CABG cohort may not necessarily be translatable to other patient populations, given that we perform the majority of these cases 'off-pump,' a practice pattern not currently adopted by most surgical centers in the United States (31). Despite our center's surgical experience, only 100 patients were treated with HCR, which reflects our selectiveness of the revascularization strategy.

\section{CONCLUSIONS}

Our results confirm that HCR is associated with excellent short-term outcomes, with a shorter length of hospital stay than traditional CABG. A HCR strategy for patients with TVD is associated with similar long-term survival and freedom from MACE to traditional CABG or multi-vessel PCI. HCR should be considered a feasible option for select patients with TVD, for those with intermediate SYNTAX scores and appropriate coronary anatomy, a proposal echoed by others $(23,31)$, presuming that a low residual SYNTAX score can be attained.

Acknowledgements: The authors are grateful to Efstathia A Mihelis and to Sridhar Uttara for their assistance in data collection and management.

\section{REFERENCES}

1. Serruys PW, Morice MC, Kappetein AP, Colombo A, Holmes DR, Mack MJ et al; SYNTAX Investigators. Percutaneous coronary intervention versus coronary-artery bypass grafting for severe coronary artery disease. N Engl J Med 2009; 360: 961-72. 
2. Farkouh ME, Domanski M, Sleeper LA, Siami FS, Dangas G, Mack M et al; FREEDOM Trial Investigators. Strategies for multivessel revascularization in patients with diabetes. N Engl J Med 2012; 367: 2375-84.

3. Tatoulis J, Buxton BF, Fuller JA. Patencies of 2127 arterial to coronary conduits over 15 years. Ann Thorac Surg 2004; 77: 93-101.

4. Desai ND, Naylor CD, Kiss A, Cohen EA, Feder-Elituv R, Miwa S et al; Radial Artery Patency Study Investigators. Impact of patient and target-vessel characteristics on arterial and venous bypass graft patency: insight from a randomized trial. Circulation 2007; 115: 684-91.

5. Kim KB, Cho KR, Jeong DS. Midterm angiographic follow-up after off-pump coronary artery bypass: serial comparison using early, 1-year, and 5-year postoperative angiograms. J Thorac Cardiovasc Surg 2008; 135: 300-7.

6. Byrne RA, Joner M, Kastrati A. Stent thrombosis and restenosis: what have we learned and where are we going? The Andreas Grüntzig Lecture ESC 2014. Eur Heart J 2015; 36: 3320-31.

7. Repossini A, Tespili M, Saino A, Kotelnikov I, Moggi A, Di Bacco L et al. Hybrid revascularization in multivessel coronary artery disease. Eur J Cardiothorac Surg 2013; 44: 288-93.

8. Adams C, Burns DJ, Chu MW, Jones PM, Shridar K, Teefy P et al. Single-stage hybrid coronary revascularization with long-term follow-up. Eur J Cardiothorac Surg 2014; 45: 438-42.

9. Thygesen K, Alpert JS, Jaffe AS, Simoons ML, Chaitman BR, White HD et al; Joint ESC/ACCF/AHA/WHF Task Force for the Universal Definition of Myocardial Infarction, Third universal definition of myocardial infarction. Circulation. 2012; 126:2020-35

10. Hillis LD, Smith PK, Anderson JL, Bittl JA, Bridges CR, Byrne JG et al; American College of Cardiology Foundation; American Heart Association Task Force on Practice Guidelines; American Association for Thoracic Surgery; Society of Cardiovascular Anesthesiologists; Society of Thoracic Surgeons. 2011 ACCF/AHA guideline for coronary artery bypass graft surgery: a report of the American College of Cardiology Foundation/American Heart Association Task Force on practice guidelines. Circulation 2011; 124: e652-735.

11. Harskamp RE, Brennan JM, Xian Y, Halkos ME, Puskas JD, Thourani VH et al. Practice patterns and clinical outcomes after hybrid coronary revascularization in the United States: an analysis from the Society of Thoracic Surgeons adult cardiac database. Circulation 2014; 130: 872-9.

12. Hemli JM, Darla LS, Panetta CR, Jennings J, Subramanian VA, Patel NC. Does body mass index affect outcomes in robotic-assisted coronary artery bypass procedures? Innovations (Phila) 2012; 7: $350-3$.

13. Hemli JM, Henn LW, Panetta CR. Defining the learning curve for robotic-assisted endoscopic harvesting of the left internal mammary artery. Innovations (Phila) 2013; 8: 353-8.

14. Subramanian VA, Loulmet DF, Patel NC. Minimally invasive coronary artery bypass grafting. Semin Thorac Cardiovasc Surg 2007; 19: 281-8.

15. Patel NC, Patel NU, Loulmet DF, McCabe JC, Subramanian VA. Emergency conversion to cardiopulmonary bypass during attempted off-pump revascularization results in increased morbidity and mortality. J Thorac Cardiovasc Surg 2004; 128: 655-61.

16. Farooq V, Girasis C, Magro M, Onuma Y, Morel MA, Heo JH et al. The CABG SYNTAX Score - an angiographic tool to grade the complexity of coronary disease following coronary artery bypass graft surgery: from the SYNTAX Left Main Angiographic (SYNTAX-LE MANS) substudy. EuroIntervention. 2013 Mar;8(11):1277-85. 
17. Harris PA, Taylor R, Thielke R, Payne J, Gonzalez N, Conde JG. Research electronic data capture (REDCap) - a metadata-driven methodology and workflow process for providing translational research informatics support. J Biomed Inform 2009; 42: 377-81.

18. Halkos ME, Rab ST, Vassiliades TA, Morris DC, Douglas JS, Kilgo PD et al. Hybrid coronary revascularization versus off-pump coronary artery bypass for the treatment of left main coronary stenosis. Ann Thorac Surg 2011; 92: 2155-60.

19. Puskas JD, Halkos ME, DeRose JJ, Bagiella E, Miller MA, Overbey J et al. Hybrid Coronary Revascularization for the Treatment of Multivessel Coronary Artery Disease: A Multicenter Observational Study. J Am Coll Cardiol. 2016 Jul 26;68(4):356-65.

20. Hemli JM, Darla LS, Panetta CR, Jennings J, Subramanian VA, Patel NC. Does dual antiplatelet therapy affect blood loss and transfusion requirements in robotic-assisted coronary artery surgery? Innovations (Phila) 2012; 7: 399-402.

21. Shen L, Hu S, Wang H, Xiong H, Zheng Z, Li L et al. One-stop hybrid coronary revascularization versus coronary artery bypass grafting and percutaneous coronary intervention for the treatment of multivessel coronary artery disease: 3-year follow-up results from a single institution. J Am Coll Cardiol. 2013 Jun $25 ; 61(25): 2525-33)$

22. Daneil WT, Liberman HA, Kilgo P, Puskas JD, Vassiliades TA, Devireddy C et al. The impact of clopidogrel therapy on postoperative bleeding after robotic-assisted coronary artery bypass surgery. Eur J Cardiothorac Surg 2014; 46: e8-13.

23. Bonatti J, Schachner T, Bonaros N, Jonetzko P, Ohlinger A, Ruetzler E et al. Simultaneous hybrid coronary revascularization using totally endoscopic left internal mammary artery bypass grafting and placement of rapamycin eluting stents in the same interventional session. The COMBINATION pilot study. Cardiology 2008; 110: 92-5.

24. Kon ZN, Brown EN, Tran R, Joshi A, Reicher B, Grant MC et al. Simultaneous hybrid coronary revascularization reduces postoperative morbidity compared with results from conventional off-pump coronary artery bypass. J Thorac Cardiovasc Surg 2008; 135: 367-75.

25. Mohr FW, Morice MC, Kappetein AP, Feldman TE, Ståhle E, Colombo A et al. Coronary artery bypass graft surgery versus percutaneous coronary intervention in patients with three-vessel disease and left main coronary disease: 5-year follow-up of the randomised, clinical SYNTAX trial. Lancet 2013; 381: 629-38.

26. Malkin CJ, George V, Ghobrial MS, Krishnan A, Siotia A, Raina T, Morton AC et al. Residual SYNTAX score after PCI for triple vessel coronary artery disease: quantifying the adverse effect of incomplete revascularisation. EuroIntervention 2013; 8: 1286-95.

27. Farooq V, Serruys PW, Bourantas CV, Zhang Y, Muramatsu T, Feldman T et al. Quantification of incomplete revascularization and its association with five-year mortality in the synergy between percutaneous coronary intervention with taxus and cardiac surgery (SYNTAX) trial: validation of the residual SYNTAX score. Circulation 2013; 128: 141-51.

28. Melina G, Angeloni E, Refice S, Benegiamo C, Lechiancole A, Matteucci M et al. Residual SYNTAX score following coronary artery bypass grafting. Eur J Cardiothorac Surg 2017; 51: 547-53.

29. Patel NC, Hemli JM, Kim MC, Seetharam K, Pirelli L, Brinster DR, Scheinerman SJ et al. Short and intermediate-term outcomes of hybrid coronary revascularization for double-vessel disease. J Thorac Cardiovasc Surg 2018; 156: 1799-1807.

30. Peterss S, Charilaou P, Ziganshin BA, Elefteriades JA. Assessment of survival in retrospective studies: the Social Security Death Index is not adequate for estimation. J Thorac Cardiovasc Surg 2017; 153: 899-901. 
31. Yanagawa B, Nedadur R, Puskas JD. The future of off-pump coronary artery bypass grafting: a North American perspective. J Thorac Dis 2016; 8: S832-8.

32. Tajstra M, Hrapkowicz T, Hawranek M, Filipiak K, Gierlotka M, Zembala M et al; POL-MIDES Study Investigators. Hybrid coronary revascularization in selected patients with multivessel disease: 5-year clinical outcomes of the prospective randomized pilot study. J Am Coll Cardiol Intv 2018; 11: 847-52.

33.

\section{FIGURE LEGENDS}

Figure 1. Flow-chart of patient selection.

$\mathrm{CABG}=$ coronary artery bypass grafting; $\mathrm{HCR}=$ hybrid coronary revascularization; $\mathrm{PCI}=$ percutaneous coronary intervention.

Figure 2. Kaplan-Meier estimates for long-term survival with number of subjects at risk and 95\% HallWellner Bands.

$\mathrm{CABG}=$ coronary artery bypass grafting; $\mathrm{PCI}=$ percutaneous coronary intervention.

Figure 3. Kaplan-Meier estimates for freedom from repeat revascularization with number of subjects at risk and 95\% Hall-Wellner Bands.

$\mathrm{CABG}=$ coronary artery bypass grafting; $\mathrm{PCI}=$ percutaneous coronary intervention.

Figure 4. Kaplan-Meier estimates for freedom from MACE with number of subjects at risk and 95\% HallWellner Bands.

$\mathrm{CABG}=$ coronary artery bypass grafting; $\mathrm{MACE}=$ major adverse cardiovascular events; $\mathrm{PCI}=$ percutaneous coronary intervention.

TABLES

Table 1. Patient demographics (prior to propensity-matching).

\begin{tabular}{|c|c|c|c|c|c|}
\hline Variable & $\begin{array}{l}\text { HCR }(n= \\
100)\end{array}$ & $\begin{array}{l}\text { CABG }(n= \\
1258)\end{array}$ & $\begin{array}{l}\text { PCI }(n= \\
2621)\end{array}$ & $\begin{array}{l}p \text { value (HCR } \\
\text { vs. CABG) }\end{array}$ & $\begin{array}{l}p \text { value }(\text { HCR } \\
\text { vs. PCI) }\end{array}$ \\
\hline $\begin{array}{l}\text { Age, years, } \\
\text { mean } \pm \text { SD }\end{array}$ & $67.5 \pm 10.1$ & $65.8 \pm 10.1$ & $66.9 \pm 11.8$ & 0.11 & 0.63 \\
\hline $\begin{array}{l}\text { Female gender, } \\
\mathrm{n}(\%)\end{array}$ & $16(16)$ & $320(25.4)$ & $771(29.4)$ & 0.04 & 0.003 \\
\hline $\begin{array}{l}\mathrm{BMI}, \mathrm{kg} / \mathrm{m}^{2} \\
\text { mean } \pm \mathrm{SD}\end{array}$ & $27.5 \pm 3.6$ & $28.2 \pm 5.7$ & $28.7 \pm 5.5$ & 0.20 & 0.023 \\
\hline $\begin{array}{l}\mathrm{LVEF}, \% \\
\text { mean } \pm \mathrm{SD}\end{array}$ & $53.3 \pm 11.0$ & $48.8 \pm 13.2$ & $51 \pm 14.4$ & 0.001 & 0.11 \\
\hline $\begin{array}{l}\text { Diabetes } \\
\text { mellitus, n (\%) }\end{array}$ & $53(53)$ & $700(55.6)$ & $1281(48.9)$ & 0.68 & 0.48 \\
\hline $\begin{array}{l}\text { Peripheral } \\
\text { vascular } \\
\text { disease, n (\%) }\end{array}$ & $10(10)$ & $155(12.3)$ & $328(12.5)$ & 0.63 & 0.54 \\
\hline $\begin{array}{l}\text { Cerebrovascular } \\
\text { disease, } \mathrm{n}(\%)\end{array}$ & $10(10)$ & $192(15.3)$ & 298 (11.4) & 0.19 & 0.87 \\
\hline $\begin{array}{l}\text { CHF (NYHA } \\
\text { III/IV), n (\%) }\end{array}$ & $16(16)$ & $281(22.3)$ & $343(13.1)$ & 0.17 & 0.37 \\
\hline $\begin{array}{l}\text { Prior MI, n } \\
(\%)\end{array}$ & $28(28)$ & $614(48.8)$ & $1066(40.7)$ & $<0.0001$ & 0.012 \\
\hline
\end{tabular}




\begin{tabular}{llllll}
\hline & HCR $(\mathbf{n}=$ & CABG $(\mathbf{n}=$ & PCI $(\mathbf{n}=$ & $p$ value (HCR & $p$ value (HCR \\
Variable & $\mathbf{1 0 0})$ & $\mathbf{1 2 5 8})$ & $\mathbf{2 6 2 1})$ & vs. CABG) & vs. PCI) \\
\hline COPD, n $(\%)$ & $2(2)$ & $70(5.6)$ & $52(2.0)$ & 0.16 & 1.0 \\
ESRD, n $(\%)$ & $3(3)$ & $49(3.9)$ & $89(3.4)$ & 1.0 & 1.0 \\
\hline
\end{tabular}

$\mathrm{BMI}=$ body mass index; $\mathrm{CABG}=$ coronary artery bypass grafting; $\mathrm{CHF}=$ congestive heart failure $\mathrm{COPD}$ $=$ chronic obstructive pulmonary disease ESRD $=$ end-stage (dialysis-dependent) renal disease HCR $=$ hybrid coronary revascularization; $\mathrm{LVEF}=$ left ventricular ejection fraction; $\mathrm{MI}=$ myocardial infarction; NYHA = New York Heart Association; PCI = percutaneous coronary intervention; SD = standard deviation; SYNTAX = SYNergy between percutaneous coronary intervention with TAXus and cardiac surgery.

Table 2. Patient demographics (after propensity-matching).

\begin{tabular}{|c|c|c|c|c|c|}
\hline Variable & $\begin{array}{l}\text { HCR }(n= \\
100)\end{array}$ & $\begin{array}{l}\text { CABG }(n= \\
100)\end{array}$ & PCI $(n=100)$ & $\begin{array}{l}p \text { value (HCR } \\
\text { vs. CABG) }\end{array}$ & $\begin{array}{l}p \text { value }(\text { HCR } \\
\text { vs. PCI) }\end{array}$ \\
\hline $\begin{array}{l}\text { Age, years, } \\
\text { mean } \pm \text { SD }\end{array}$ & $67.5 \pm 10.1$ & $67.0 \pm 9.3$ & $67.8 \pm 10.5$ & 0.97 & 0.80 \\
\hline $\begin{array}{l}\text { Female gender, } \\
\mathrm{n}\end{array}$ & 16 & 11 & 16 & 0.41 & 1.0 \\
\hline $\begin{array}{l}\mathrm{BMI}, \mathrm{kg} / \mathrm{m}^{2} \\
\text { mean } \pm \mathrm{SD}\end{array}$ & $27.5 \pm 3.6$ & $27.7 \pm 5.0$ & $27.5 \pm 4.8$ & 0.67 & 0.97 \\
\hline $\begin{array}{l}\mathrm{LVEF}, \%, \\
\text { mean } \pm \mathrm{SD}\end{array}$ & $53.3 \pm 11.0$ & $52.5 \pm 10.7$ & $54.5 \pm 11.3$ & 0.61 & 0.45 \\
\hline $\begin{array}{l}\text { SYNTAX } \\
\text { score, mean } \pm \\
\text { SD }\end{array}$ & $28.9 \pm 10.6$ & $32.2 \pm 7.9$ & $22.1 \pm 7.6$ & 0.018 & $<0.01$ \\
\hline $\begin{array}{l}\text { Diabetes } \\
\text { mellitus, n }\end{array}$ & 53 & 47 & 50 & 0.48 & 0.78 \\
\hline $\begin{array}{l}\text { Peripheral } \\
\text { vascular } \\
\text { disease, } \mathrm{n}\end{array}$ & 10 & 6 & 11 & 0.44 & 1.0 \\
\hline $\begin{array}{l}\text { Cerebrovascular } \\
\text { disease, } n\end{array}$ & 10 & 7 & 11 & 0.61 & 1.0 \\
\hline $\begin{array}{l}\text { CHF (NYHA } \\
\text { III/IV), n }\end{array}$ & 16 & 13 & 13 & 0.69 & 0.69 \\
\hline Prior MI, n & 28 & 31 & 29 & 0.76 & 0.95 \\
\hline COPD, n & 2 & 2 & 0 & 1.0 & 0.50 \\
\hline ESRD, n & 3 & 3 & 3 & 1.0 & 1.0 \\
\hline
\end{tabular}

$\mathrm{BMI}=$ body mass index; $\mathrm{CABG}=$ coronary artery bypass grafting; $\mathrm{CHF}=$ congestive heart failure; $\mathrm{COPD}$ $=$ chronic obstructive pulmonary disease; ESRD = end-stage (dialysis-dependent) renal disease; HCR = hybrid coronary revascularization; $\mathrm{LVEF}=$ left ventricular ejection fraction; $\mathrm{MI}=$ myocardial infarction; NYHA = New York Heart Association; PCI = percutaneous coronary intervention; SD = standard deviation; SYNTAX = SYNergy between percutaneous coronary intervention with TAXus and cardiac surgery.

Table 3. Short-term outcomes 


\begin{tabular}{|c|c|c|c|c|c|}
\hline Variable & $\begin{array}{l}\text { HCR }(n= \\
100)\end{array}$ & $\begin{array}{l}\text { CABG }(n= \\
100)\end{array}$ & PCI $(n=100)$ & $\begin{array}{l}p \text { value (HCR } \\
\text { vs. CABG) }\end{array}$ & $\begin{array}{l}p \text { value }(\text { HCR } \\
\text { vs. } \mathbf{P C I})\end{array}$ \\
\hline $\begin{array}{l}\text { 30-day } \\
\text { mortality, n }\end{array}$ & 0 & 0 & 0 & 1.0 & 1.0 \\
\hline Stroke, $\mathrm{n}$ & 0 & 0 & 0 & 1.0 & 1.0 \\
\hline $\begin{array}{l}\text { Peri- } \\
\text { procedural MI, } \\
\mathrm{n}\end{array}$ & 0 & 0 & 0 & 1.0 & 1.0 \\
\hline $\begin{array}{l}\text { New-onset } \\
\text { renal failure, n }\end{array}$ & 0 & 0 & 0 & 1.0 & 1.0 \\
\hline $\begin{array}{l}\text { Length of stay, } \\
\text { days, mean } \pm \\
\text { SD }\end{array}$ & $5.7 \pm 7.5$ & $7.5 \pm 3.4$ & $2.0 \pm 2.2$ & 0.001 & $<0.0001$ \\
\hline $\begin{array}{l}\text { Length of stay, } \\
\text { days, median } \\
\text { (IQR) }\end{array}$ & $5(4$ to 6$)$ & $6(5$ to 9$)$ & $1(1$ to 2$)$ & $\mathrm{n} / \mathrm{a}$ & $\mathrm{n} / \mathrm{a}$ \\
\hline $\begin{array}{l}\text { Residual } \\
\text { SYNTAX } \\
\text { score, mean } \pm \\
\text { SD }\end{array}$ & $4.5 \pm 4.4$ & $5.2 \pm 4.7$ & $7.1 \pm 6.5$ & 0.31 & 0.001 \\
\hline
\end{tabular}

$\mathrm{CABG}=$ coronary artery bypass grafting; $\mathrm{HCR}=$ hybrid coronary revascularization; IQR $=$ interquartile range; $\mathrm{MI}=$ myocardial infarction; $\mathrm{n} / \mathrm{a}=$ not applicable; $\mathrm{PCI}=$ percutaneous coronary intervention; SD = standard deviation; SYNTAX = SYNergy between percutaneous coronary intervention with TAXus and cardiac surgery.

Table 4. Long-term outcomes

\begin{tabular}{|c|c|c|c|c|c|}
\hline Variable & $\begin{array}{l}\text { HCR }(\mathrm{n}= \\
100)\end{array}$ & $\begin{array}{l}\text { CABG }(\mathrm{n}= \\
100)\end{array}$ & PCI $(n=100)$ & $\begin{array}{l}p \text { value (HCR } \\
\text { vs. CABG) }\end{array}$ & $\begin{array}{l}p \text { value }(\text { HCR } \\
\text { vs. } \mathbf{P C I})\end{array}$ \\
\hline Mortality, n & 5 & 4 & 9 & 1.0 & 0.41 \\
\hline $\begin{array}{l}\text { Repeat revas- } \\
\text { cularization, } \\
\mathrm{n}\end{array}$ & 16 & 11 & 18 & 0.41 & 0.85 \\
\hline $\begin{array}{l}\text { Target vessel } \\
\text { revasculariza- } \\
\text { tion, n } \\
*\end{array}$ & 6 & 5 & 10 & 1.0 & 0.44 \\
\hline $\begin{array}{l}\text { Myocardial } \\
\text { infarction, n }\end{array}$ & 4 & 3 & 5 & 1.0 & 1.0 \\
\hline MACE, n + & 21 & 15 & 25 & 0.36 & 0.61 \\
\hline
\end{tabular}

$\mathrm{CABG}=$ coronary artery bypass grafting; $\mathrm{HCR}=$ hybrid coronary revascularization; $\mathrm{MACE}=$ major adverse cardiovascular events; PCI = percutaneous coronary intervention.

* Target vessel revascularization defined as repeat revascularization on a coronary artery that has already been previously treated during the index procedure.

+ MACE denotes a composite end-point encompassing death, repeat revascularization, myocardial infarction. 
All triple-vessel coronary disease (2009 - 2016) $n=4805$
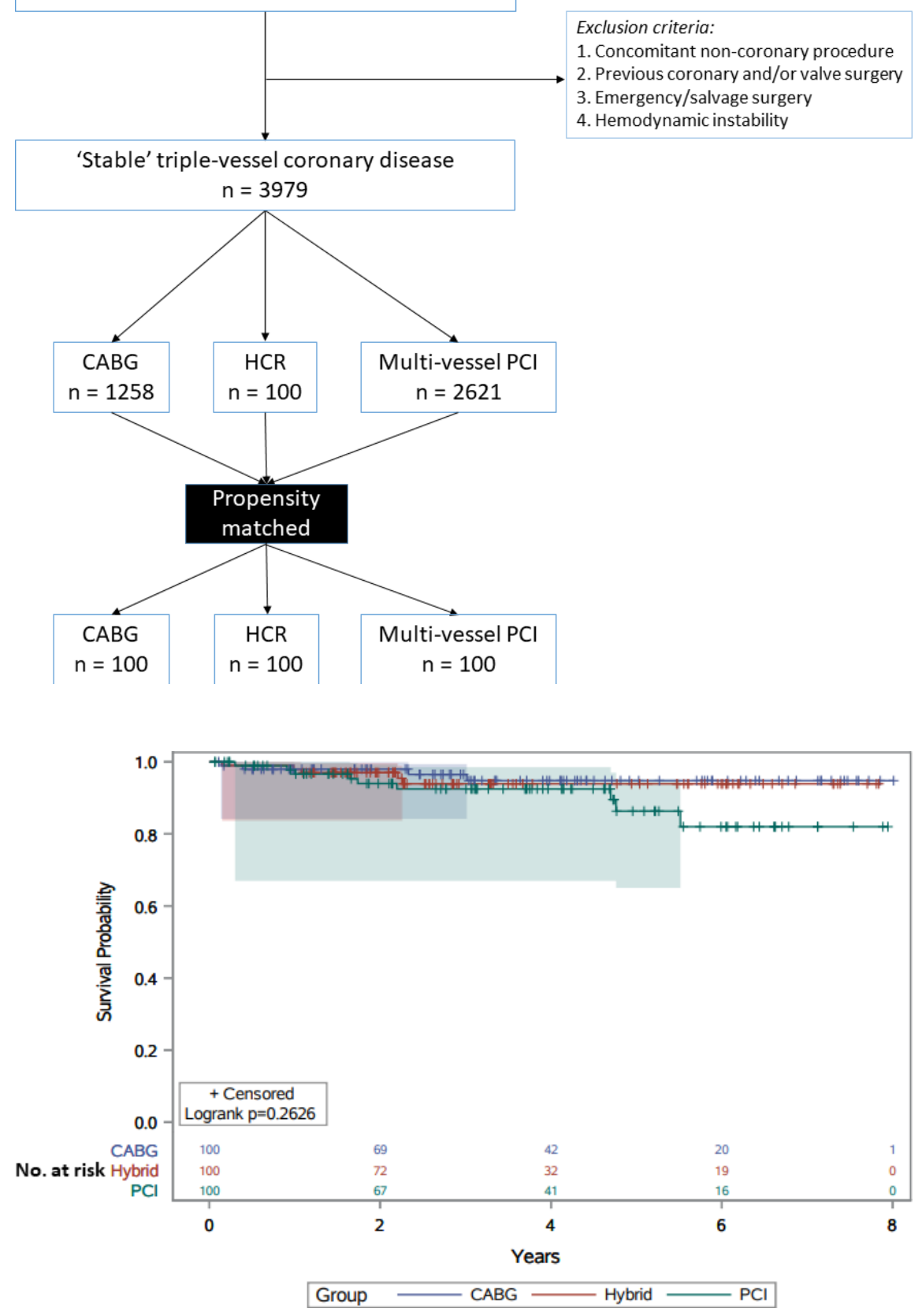

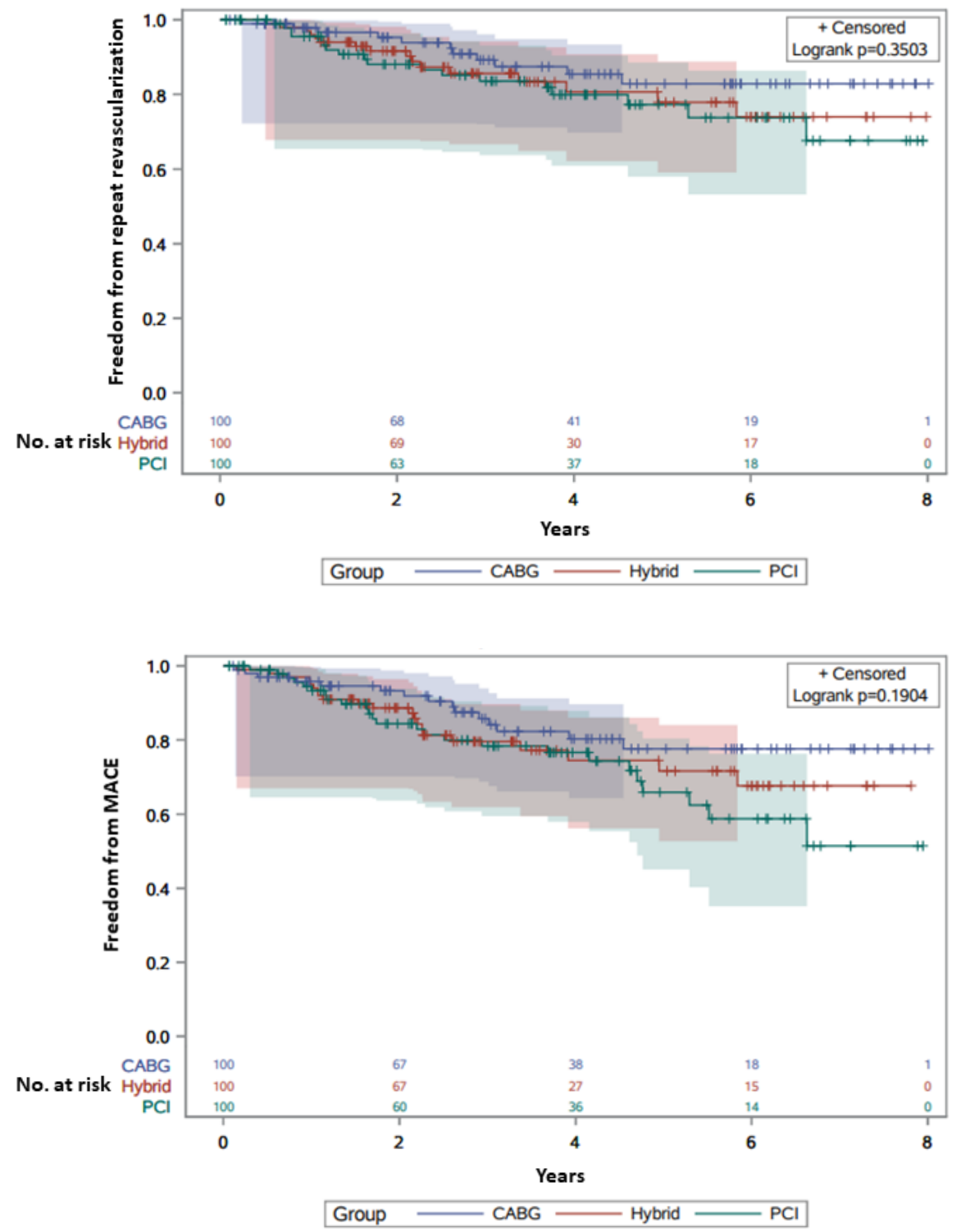

\section{Hosted file}

Table 1.docx available at https://authorea.com/users/330607/articles/457403-long-termsurvival-in-triple-vessel-disease-hybrid-coronary-revascularization-compared-tocontemporary-revascularization-methods

\section{Hosted file}

Table 2.docx available at https://authorea.com/users/330607/articles/457403-long-termsurvival-in-triple-vessel-disease-hybrid-coronary-revascularization-compared-tocontemporary-revascularization-methods

\section{Hosted file}

Table 3.docx available at https://authorea.com/users/330607/articles/457403-long-termsurvival-in-triple-vessel-disease-hybrid-coronary-revascularization-compared-tocontemporary-revascularization-methods 


\section{Hosted file}

Table 4.docx available at https://authorea.com/users/330607/articles/457403-long-termsurvival-in-triple-vessel-disease-hybrid-coronary-revascularization-compared-tocontemporary-revascularization-methods 